virulent infections. At a time when more mothers should be encouraged to breast-feed their babies ${ }^{4}$ they should not lightly be advised to stop nursing at the first sign of infection.

${ }^{1}$ Department of Health and Social Security Report on Present-Day Practice in Infant Feeding. London, HMSO, 1974.

Prothero, R, Medical Officer, 1969, 121, 141

3 Sleigh, G, and Ounsted, M, Lancet, 1975, 1, 753.

Sloper, K, McKean, L, and Baum, J D, Archives of Disease in Childhood, 1975, 50, 165.

5 Jeffrey, J S, Edinburgh Medical fournal, 1947, 54, 442

${ }^{6}$ Fulton, A A, British Medical fournal, 1945, 1, 693.

7 Applebaum, R M, Pediatric Clinics of North America, 1970, 17, 203.

${ }^{8}$ Vorherr, H, fournal of the American Medical Association, 1974, 227, 676.

9 Marshall, B R, Hepper, J K, and Zirbel, C C, Fournal of the American Medical Association, 1975, 233, 1377.

10 Gibberd, G F, American Fournal of Obstetrics and Gynecology, 1953, 65, 1038.

${ }^{11}$ Duncan, J T, and Walker, J, fournal of Hygiene, 1942, 42, 474.

12 Colbeck, J C, Canadian Medical Association fournal, 1949, 61, 557.

${ }^{13}$ Ravenholt, R T, Wright, P, and Mulhern, M, New England fournal of Medicine, 1957, 257, 789

14 Taylor, M D, and Way, S, British Medical fournal, 1946, 2, 731.

${ }^{15}$ Devereux, W P, American Fournal of Obstetrics and Gynecology, 1970, $108,78$.

16 Goodman, M A, and Benson, E A, Medical fournal of Australia, 1970, 1, 1034.

17 Walsh, A, Lancet, 1949, 2, 635.

18 Varga, L, et al, British Medical fournal, 1972, 2, 743.

9 Huai-Chin, H, Chinese Medical fournal, 1973, 11, 152.

20 Newton, M, and Newton, N R, Surgery, Gynecology and Obstetrics, 1950, 91, 651.

21 Bates, T, et al, Practitioner, 1973, 211, 541.

22. Stammers, F A R, British Medical fournal, 1953, 1, 272.

23 Vanina, L V, and Chumak, T F, Akusherstvo i Ginekologiia (Moskva), 1973, 49, 48.

\section{When should regular dialysis therapy start?}

For most dialysis units the time of starting patients with chronic uraemia on regular dialysis is decided by logistics rather than a precise knowledge and control of the factors determining the best time. There can be few nephrologists who have not been obliged to practise the art of brinkmanship as they have tried to fit the queue of patients with progressive end-stage renal failure into the barely adequate, or in some cases inadequate, facilities at their disposal. Without doubt in the past many patients were too uraemic for too long and had of necessity existed on a severely restricted protein intake before a place could be found for them on a dialysis programme. Neither survival nor rehabilitation could be optimal in such circumstances.

Precise information about when nephrologists start their patients on regular dialysis therapy is not easy to come by. In most British units, as elsewhere, patients generally seem to start dialysis when the creatinine clearance is beginning to fall below $5 \mathrm{ml}$ min at a time when clinical manifestations of uraemia are becoming more troublesome for the patient. Often, however, the clinician has no choice in the matter; he first sees the patient in far advanced end-stage renal failure in circumstances where there is little scope for manoeuvre. In all cases before a final decision is taken to begin dialysis the nephrologist will have looked for, and corrected if possible, the presence of any reversible factors such as salt or water depletion, severe hypertension, obstruction within the urinary tract, analgesic abuse, and renal and systemic infection.

Bonomini and his colleagues ${ }^{1}$ have recently put forward the provocative suggestion that we are still not doing well enough for our patients by delaying the start of regular dialysis therapy until the creatinine clearance has fallen to around or below
$5 \mathrm{ml} / \mathrm{min}$. In a retrospective analysis of about 150 patients they compared the outcome in those who started dialysis when the creatinine clearance had fallen to between 0 and $5 \mathrm{ml} / \mathrm{min}$, those with clearances of $5-15 \mathrm{ml} / \mathrm{min}$, and those with clearances at the start of dialysis of between $15-21 \mathrm{ml} / \mathrm{min}$. They concluded that the patients who started dialysis with the highest residual creatinine clearances did best, in terms of both survival and rehabilitation. This is perhaps a not surprising conclusion, since clearly the benefits of a residual renal function of, say, $15 \mathrm{ml} / \mathrm{min}$ will almost invariably mean one is dealing with a fitter group of patients. Furthermore, such patients will not have the same problems of fluid restriction, sodium restriction, and potassium restriction that must be faced by the severely oliguric or anuric individual with negligible renal function.

The Italian study is open to criticism: it has some of the defects associated with all retrospective analyses, and the dialysis schedules in the different groups of patients were not identical. It is even more likely to invite criticism because of the formidable logistic problem that adoption of its conclusions would inevitably bring, particularly when there is no room in most countries for complacency with the number of patients with end-stage renal failure who receive treatment by dialysis or transplantation. Study of the data ${ }^{2}$ of the registration committee of the European Dialysis and Transplant Association for the year ending 1973 showed that the United Kingdom was about middle of the league table, providing treatment for 46 patients per million of the population compared with the Danish figure of 104. Nevertheless, the argument that regular dialysis therapy should be started at an earlier stage than is the general practice throughout the world, though not necessarily as early as Bonomini advocates, should not be dismissed out of hand. Starting of dialysis at creatinine clearance values somewhat above $5 \mathrm{ml}$ min rather than distinctly below that level would undoubtedly mean a smoother start to treatment and a lower incidence of complications for most patients. Unfortunately, hard realities make such a policy a luxury that few countries will be able to indulge in.

\footnotetext{
${ }^{1}$ Bonomini, V, et al, Nephron, 1976, 16, 89.

2 Parsons, F M, et al, in Dialysis, transplantation, nephrology: Proceedings of the European Dialysis and Transplant Association, II, ed J F Moorhead. London, Pitman, 1974.
}

\section{Pancreatic pain}

Pain arising from a diseased pancreas may be both severe and very persistent. At times it is quite crippling, and its management presents a difficult problem which can test the ingenuity of the treating physician. The exact mechanism of the pain is not clearly understood, but it may arise either because of partial or complete blockage of the pancreatic duct, leading to distension, or because of inflammation of the peripancreatic nerves or their infiltration by malignant tissue. The afferent pathway from the pancreas passes to the coeliac plexus and then via the right and left splanchnic nerves to the right and left 6-11th sympathetic ganglia. There is some lateralisation of distribution-most fibres from the head of the gland pass to the right side and most from the tail to the left-but this separation is not absolute. ${ }^{1}$

Chronic upper abdominal pain cannot certainly be attributed to pancreatic disease short of a laparotomy, but in most cases it can be identified as pancreatic because it is constant and 
the fact that the pain is usually referred to the back, and also because it is often relieved by forward flexion. Assessment of its severity, particularly in patients with chronic relapsing pancreatitis, is frequently made more difficult because there may be some psychological overlay or a problem of drug addiction.

Pancreatic pain may be relieved by drugs, by decompression of the duct of Wirsung, by pancreatic resection, or by interruption of the afferent nerve supply. Control of pain by analgesics is clearly the method of choice in acute pancreatitis because the symptoms are of limited duration. In severe cases small doses of diamorphine may be given intravenously at regular intervals and so be titrated against the level of the pain. However, in patients with chronic relapsing disease or carcinoma drug addiction may develop rapidly, and in general those who need the frequent use of morphine or its derivatives should be considered for alternative forms of pain relief. Various cytotoxic drugs, and in particular 5-fluorouracil, have been used in an attempt to palliate the pain of pancreatic malignancy. In general the results have been disappointing until quite recently, when Gazet and Smith ${ }^{2}$ reported a worthwhile relief of pain in $54 \%$ of cases, but their method of administration of the drug required it to be given by direct injection through a catheter positioned in the common hepatic artery. Combinations of chemotherapeutic agents are under study by cooperative oncology groups in the USA at present. ${ }^{3}$ No firm results are yet available, but preliminary analysis suggests that a combination of 5-fluorouracil with streptozotocin has produced the most effective palliation.

Pancreatic duct decompression is clearly effective in the treatment of patients with chronic relapsing pancreatitis in whom the duct of Wirsung is dilated, and particularly if a pseudocyst is present. ${ }^{4}$ Recent observations suggest, however, that the anastomosis between the pancreatic duct and the bowel may not remain patent and that separation of the Roux loop may occur, though this is not always associated with a return of symptoms. ${ }^{5}$ Pancreaticojejunostomy is another accepted procedure for the relief of the pain due to obstruction of the duct by a carcinoma in the head of the gland. ${ }^{6}$ However, the results of this operation are variable: it is not always possible to assess how much of the pain is due to the duct distension and how much to malignant infiltration of the gland and surrounding tissues. ${ }^{7}$

Pancreatic resection plays little or no part in the treatment of pain due to an established pancreatic carcinoma, for by th.t time the growth is usually inoperable. When, however, a resection has been performed for an apparently operable carcinoma the development of pancreatic pain is often delayed subsequently and may not occur at all, even though the patient succumbs to the malignancy. ${ }^{8}$ Resection finds its main value in the treatment of patients with chronic relapsing pancreatitis, ${ }^{4}$ and in particular the operation of $95 \%$-subtotal pancreatectomy is useful. ${ }^{9}$ The selection of patients and the actual technique of the operation both present some difficulties, but for the patient who is crippled by the pain of chronic relapsing pancreatitis alone it is a very worthwhile procedure.

Interruption of the pain-carrying afferent fibres from the pancreas is a further alternative method of treatment. Splanchnicectomy was popularised by Mallet-Guy and De Beaujeu, ${ }^{10}$ but the long-term results have not stood the test of time and the operation has now been largely abandoned. ${ }^{811}$ Recently Kune et $a l^{7}$ have reported encouraging results from the use of a carefully controlled coeliac plexus block. They recommend that with the patient anaesthetised and lying prone a needle may be introduced under $x$-ray control into the region of the splanchnic nerves antrolateral to $\mathrm{Ll} ; 10 \mathrm{ml}$ of absolute alcohol may then be injected into each side. After the injection the patient should be nursed flat for 24 hours, for temporary postural hypotension is common. Of 25 patients treated 19 had their pain relieved. The group included 12 patients with proved carcinoma, of whom 10 achieved considerable relief, and there were 8 patients with chronic relapsing disease, 6 of whom were benefited by the injection. In the remaining 5 patients the pain was not clearly pancreatic; 3 of these obtained good relief, and Kune and his colleagues comment that coeliac plexus block may therefore be used diagnostically as well as therapeutically in this group of cases so that the patient may be saved an exploratory laparotomy.

With the establishment of pain clinics in many hospitals this Australian experience is of special interest, and it should give impetus to an additional method of treatment of a distressing and otherwise intractable symptom.

\footnotetext{
${ }^{1}$ Bliss, W R, et al, Gastroenterology, 1950, 16, 317.

2 Gazet, J C, and Smith, R, Proceedings of the Royal Society of Medicine, $1974,67,1182$.

3 Carter, S K, and Comis, R L, Cancer Treatment Reviews, 1975, 2, 193.

4 Leger, L, Lenriot, J P, and Lemaigre, G, Annals of Surgery, 1974, 180, 185.

5 Trapnell, J E, 1975, communication to Annual Meeting, University Surgeons of France, Rennes.

${ }^{6}$ Elmslie, R G, and Slavotinek, A H, British fournal of Surgery, 1972, 59, 508.

' Kune, G A, Cole, R, and Bell, S, Medical fournal of Australia, 1975, 2, 789.

${ }^{*}$ Smith, R, 1975, unpublished information.

${ }^{9}$ Child, C G, Frey, C F, and Fry, W J, Surgery, Gynecology and Obstetrics, 1969, 129, 49.

10 Mallet-Guy, P, and de Beaujeu, M J, Lyon Chirurgical, 1952, 47, 531.

11 Warren, K W, and Mountain, J C, Surgical Clinics of North America, 1971, 51, 693.
}

\section{Early diagnosis of rheumatoid arthritis}

There is little difficulty in diagnosing fully fledged rheumatoid arthritis. The American Rheumatism Association has laid down accepted criteria, ${ }^{1}$ which are useful for epidemiological purposes in that they enable research workers to speak a common language. Though accepted, the criteria are not entirely acceptable in that they attach equal weight to each feature: thus one swollen joint scores as much as a pathognomonic subcutaneous nodule.

Early diagnosis is a greater problem. The signs of rubella synovitis, for instance, may be exactly like those of rheumatoid arthritis. ${ }^{2}$ Bayliss $e t ~ a l^{3}$ have recently evaluated selected laboratory procedures in early diagnosis in a prospective three-year study of 85 patients with effusions of the knee. Histopathological examination of samples of synovial membrane obtained by needle biopsy proved a sensitive but not entirely specific test. This was somewhat at variance with the findings of others who used a punch ${ }^{4-6}$ or needle biopsy. ${ }^{7-10}$ The changes considered suggestive of rheumatoid arthritis (RA) were synovial hyperplasia; increased vascularity; infiltration with mononuclear cells (particularly around vessels and occasionally as discrete aggregates); and fibroblastic and mononuclear cuffing of small vessels. ${ }^{11}$ Using these pathological criteria, the Perth group ${ }^{3}$ found that $77 \%$ of those graded as RA-positive later developed clinical rheumatoid arthritis-but so also did $16 \%$ of those graded as RA-negative.

Immunofluorescence proved of further help. The staining pattern varied, but the most distinctive feature was the presence of a circular ring of staining which appeared to be 